clinicians' resistances to implementation of research findings regarding antipsychotic prescribing. This is not new and similar findings were reported throughout the 1980 s including a follow-up survey demonstrating lack of change in practice over the time during which a number of such studies were published (Clark \& Holden, 1987). Nonetheless polypharmacy and prescription of high dosage still persist across the psychiatric specialities and age ranges (e.g. Lowe et al, 1996) despite evidence that clinical audit can be an effective vehicle of change of prescribing habits (Warner et al, 1995). Surely the implicit challenge that Chaplin \& McGuigan lay down is that it may be our anxieties and "need to do something" when confronted by chronic illness or risk of harm to self or others that influence some of our treatment decisions more than our knowledge base. Education, provision of information and even audit acitivities will not produce change without an openness to examine not just our practices but also our underlying motivations and feelings.

Clark. A. F. \& Holden, N. L. (1987) The persistence of prescribing habits: a survey and follow-up of prescribing to chronic hospital in-patients. British Journal of Psychiatry, 160, 88-91.

LOWE, K., SMITH, H. \& ClARK, A. (1996) Neuroleptic prescribing in an adolescent psychiatric in-patient unit. Psychiatric Bulletin 20. 538-540.

WARNER, J. P., SLADE, R. \& BARNES, T. R. E. (1995) Change in neuroleptic prescribing practice. Psychiatric Bulletin 18. 237-239.

ANDREW CLARK, Parkview Clinic, 60 Queensbridge Road, Moseley, Birmingham B13 8QE

\section{Highly specialised services}

Sir: Recent articles on this topic (Psychiatric Bulletin, November 1995, 19, 657-659; March 1996, 20, 129-130) require further comments. First, I add two such services not listed:

(i) Gender identity disorders

(ii) Psychosurgery

I have been able, with considerable cooperation from colleagues in a variety of fields, to establish services on a regional basis for both these services; they have been well used in terms of referral from colleagues.

The first of the Bulletin articles raises the topic of the future of specialised services once the originator retires. As the date for my retirement hoves into sight the question of the future for these services is now under discussion. Lack of experience of the work is likely to be a factor inhibiting potential applicants. My colleagues and I have recognised the importance of a long handover period during which a successor may observe and acquire the relevant knowledge in order to conduct the service in which he/she has a potential for interest. This fact must be observed if a special service is to continue.

R. P. SNATH, Senior Lecturer and Honorary Consultant Psychiatrist, University of Leeds, Clinical Sciences Building. St James's University Hospital, Leeds LS9 TTF

\section{Suicide in the severely mentally ill}

Sir: A retrospective review of suicide in in-patient units was initiated in the Northern Region, in view of the recent interest in suicide in the severely mentally ill, and revealed 24 suicides of in-patients of psychiatric units between 1991 and 1993, of which 22 cases were audited. Eight $(36 \%)$ of the study population had a diagnosis of depression (ICD-10). Results indicated that five out of eight $(63 \%)$ of this group committed suicide between the hours of 12 midnight and $6 \mathrm{am}$. If bipolar depressed patients were excluded from the depression group four out of five (80\%) committed suicide between these times. This suggests that higher levels of observation are required for depressed patients in hospital in the early morning when staffing levels are normally at their lowest.

Half of all depressed patients were outside the hospital at the time of suicide. Two were on agreed leave and two were absent without leave. Similar findings were reported by the recently published Confidential Inquiry into Homicides and Suicides by Mentally IIL People (Royal College of Psychiatrists, 1996). This would indicate that greater vigilance has to be exercised in authorising leave in patients suffering from depression, particularly those who have, in the past, been considered to be a serious suicide risk. For example, one patient granted leave had made three previous attempts on her life by hanging, drowning and poisoning by car exhaust fumes.

Although suicide is a rare event and therefore the numbers of patients reviewed were only small, the audit does highlight a group of patients who appear to be at greater risk. The degree of supervision on discharge from a ward is critical and should involve other agencies outside the hospital such as GPs, CPNs and also the relatives. It is recommended that future audit programmes assess the effectiveness of leave arrangements prior to the patient being granted any home leave, especially for depressed or previously suicidal patients.

SuE JACKSON, Regional Clinical Audit Officer, KEN DAVISON, DONALD ECCLESTON, The Royal Victoria Infirmary. Newcastle upon Tyne NE1 4LP 